\title{
Consequências da pandemia da covid-19 para as pessoas do setor de turismo na região Bonito/Serra da Bodoquena
}

\author{
Consequences of the covid-19 pandemic for people in the tourism sector in the Bonito/Serra da Bodoquena region \\ Consecuencias de la pandemia de covid-19 para las personas del el sector turístico en la región de Bonito/Serra da \\ Bodoquena
}

Joyce Avila de Oliveira

Instituto Federal de Educação do Mato Grosso do Sul

(IFMS), Brasil

DOI: https://doi.org/10.18472/cvt.21n3.2021.1981

Redalyc: https://www.redalyc.org/articulo.oa?

$\mathrm{id}=115469516005$

Amilton Luiz Novaes
Universidade Federal da Grande Dourados (UFGD),
Brasil

Edvaldo Cesar Moretti

Universidade Federal da Grande Dourados (UFGD), Brasil

\section{Resumo:}

O objetivo do artigo é analisar as consequências da pandemia da covid-19, especificamente, no setor de turismo dos municípios de Bodoquena, Bonito e Jardim, no Mato Grosso do Sul, por meio de levantamento, sistematização e análise de dados qualiquantitativos de órgãos oficiais e aplicação de questionário e entrevistas junto a guias de turismo, empresários do setor turístico e representantes de órgãos governamentais. $\mathrm{O}$ setor do turismo, no período analisado, foi encerrado por três meses, acarretando prejuízos para os trabalhadores, que permaneceram sem renda, ainda que alguns tenham realizado atividades diversas para obtê-la. Foi constatado que os trabalhadores do turismo e as empresas turísticas não receberam apoio direto dos órgãos públicos no período de fechamento das atividades. No retorno destas, o setor percebeu mudança no perfil do visitante com o aumento da participação de turistas de cidades do próprio estado. Também, foi observada a valorização dos destinos de natureza, com hospedagens isoladas, acesso privado a elementos da natureza como rios e áreas de matas.

PalaVras-chave: Turismo, covid-19, Bonito/Serra da Bodoquena.

\section{Abstract:}

The objective of the article is to analyze the consequences of the Covid-19 pandemic, specifically, in the tourist sector of the cities of Bodoquena, Bonito and Jardim, in Mato Grosso do Sul, through data collection in official agencies and application of questionnaires and interviews together with tour guides, businessmen in the tourism sector and representatives of government agencies. The quali-quantitative data were systematized in tables and the analyzes considered the official data and the results of the questionnaire. The tourism sector in the analyzed period closed for three months, causing losses for workers who remained without income during this period, even though some have carried out different activities to obtain some income. It was found that tourism workers and tourist companies did not receive direct support from public agencies during the closing period of activities. In the return of activities, the sector noticed a change in the visitor profile with the increase in the participation of tourists from cities in the state itself. It is also noticeable the appreciation of nature destinations, with isolated accommodation, private access to elements of nature such as rivers and forest areas.

KEYWORDS: tourism, Covid-19, Bonito/Serra da Bodoquena.

\section{Resumen:}

El objetivo del artículo es analizar las consecuencias de la pandemia Covid-19, específicamente, en el sector turístico de los municipios de Bodoquena, Bonito y Jardim, en el Mato Grosso do Sul, a través de la recolección de datos en organismos oficiales y aplicación de cuestionarios y entrevistas con guías turísticos, empresarios del sector turístico y representantes de agencias 
gubernamentales. Los datos cualitativos y cuantitativos se sistematizaron en tablas y los análisis consideraron datos oficiales y los resultados del cuestionario. El sector turístico en el período analizado cerró por tres meses, resultando en pérdidas para los trabajadores que permanecieron sin ingresos durante este período, aunque algunos han realizado diferentes actividades para obtener algún ingreso. Fue averiguado que los trabajadores del turismo y las empresas turísticas no recibieron apoyo directo de los organismos públicos durante el período de cierre de actividades. Al regreso de las actividades, el sector notó un cambio en el perfil del visitante con el aumento de la participación de turistas de ciudades del propio estado. También es notable la apreciación de los destinos naturales, con alojamiento aislado, acceso privado a elementos de la naturaleza como ríos y áreas forestales.

Palabras Clave: turismo, covid-19, Bonito/Serra da Bodoquena.

\section{INTRODUÇÃo}

Ao passo que um coronavírus irrompe o mundo, no ano de 2020, caracterizando uma pandemia, sua disseminação repercute nas atividades econômicas e sociais. No período que este texto foi produzido, a sociedade ainda continua refém da circulação do vírus devido à baixa imunização. Com objetivo de compreender os diversos impactos que a pandemia gerou na atividade turística da região Bonito/Serra da Bodoquena, esta pesquisa desenvolve-se junto ao Grupo de Pesquisa "Turismo em tempos de pandemia uma abordagem geográfica multi e trans-escalar"[1].

Os impactos da pandemia iniciada em março de 2020, no Brasil, foram sentidos nas mais diversas áreas, como economia, saúde, educação, entre outros, e têm sido amplamente debatidos. Para Abbas et al. (2021) o turismo e o lazer tem sido uma das atividades mais afetadas, considera ainda que o comportamento das partes interessadas no turismo e as investigações no campo da covid-19 são críticas, visto que tais interessados, particularmente os trabalhadores do turismo, muitas vezes, não estão incluídos nas análises. O que propomos, neste texto, é analisar o reflexo da pandemia no turismo por meio dos atores envolvidos na atividade. Ou seja, lançar um olhar para tais impactos produzidos na vida de quem trabalha com o turismo e compreender, a partir de sua perspectiva, como a pandemia da covid-19 afetou o setor turístico em diferentes localidades do mundo.

Após o início da pandemia, sem ações firmes e concretas de prevenção e sem a disponibilidades de vacinas, intervenções foram realizadas, medidas de confinamento (lockdown) foram adotadas, restrições a circulação de pessoas e conseguentemente dos fluxos turisticos (Gossling; Scott; Hall, 2020). No Brasil, a interrupção de diversas atividades consideradas não essenciais foi recomendada e instituída pela Lei $n^{\circ} 13.979$, de 6 de fevereiro de 2020, que "[...] dispõe sobre as medidas para enfrentamento da emergência de saúde pública de importância internacional [...]" (Brasil, 2020a). No entanto, o que caracterizou efetivamente o início da pandemia no Brasil, criando um marco temporal, foi a Portaria n ${ }^{\circ} 454$, de 20 de março de 2020, do Ministério da Saúde, apontando que "[...] o país se encontrava em estado de transmissão comunitária do coronavírus (covid-19)" (Brasil, 2020b) e agravando a necessidade de enfrentamento, o que levou ao isolamento social.

A caracterização da pandemia delimita nosso recorte temporal, todavia, também demarcamos geograficamente nossa pesquisa na Região Turística Bonito/Serra da Bodoquena, Mato Grosso do Sul (MS). Essa região turística recebe anualmente um número expressivo de turistas, considerando o quadro turístico do MS, que em grande parte devem-se às suas paisagens naturais e estrutura turística.

O município de Bonito liderou, no primeiro trimestre do ano de 2019 (janeiro a março), o ranking dos municípios mais visitados do referido estado, de acordo com boletim trimestral do Observatório do Turismo de Mato Grosso do Sul (Observatório do Turismo de MS, 2019). No primeiro trimestre de 2020, Bonito correspondeu a segunda cidade de destino dos desembarques (39,19\%), quase equiparada à cidade de Campo Grande (39,8\%), conforme dados do mesmo Observatório. Além disso, ocorreu retração de 19,19\% no quantitativo de desembarques em relação ao mesmo período de 2019 (Observatório do Turismo de MS, 2020), aparecendo, assim, os primeiros impactos da pandemia, devido às manifestações de casos da doença no Brasil e no estado do Mato Grosso do Sul. 
No ano de 2019, o Ministério do Turismo apresentou o Programa Investe Turismo que, apesar de utilizar como base as regiões turísticas inseridas no mapa do turismo brasileiro, apenas 30 foram contempladas, sendo uma delas a região turística Bonito/Serra da Bodoquena (Brasil et al., 2019). Mas devido aos critérios de escolha - ou seja, possuir patrimônios mundiais da humanidade, possuir pelo menos um destino consolidado no mercado internacional, a presença de aspectos como venda conjunta, acesso, conectividade e existência de projetos de consolidação das rotas como produto turístico - apenas 3 municípios da região foram efetivamente inseridos no Programa: Bonito (classificação B), Jardim (classificação C) e Bodoquena (Classificação D) (Brasil et al., 2019; Brasil; Mtur, 2019).

A proposta de regionalizar o turismo surge em 2004 com o Programa de Regionalização do Turismo (PRT), sendo inicialmente apresentado um primeiro mapa de regionalização, no qual a Região de Bonito/ Serra da Bodoquena compreende, além dos municípios citados acima, Bela Vista (Categoria D), Nioaque (Categoria D) e Porto Murtinho (Categoria D). As bases do Programa de Regionalização do Turismo derivam do Macroprograma 4 - Estruturação e Diversificação da Oferta Turística, do Plano Nacional de Turismo (PNT) em vigor nos anos de 2003-2007. No âmbito do Programa de Regionalização do Turismo, regionalizar significa:

[...] transformar a ação centrada na unidade municipal em uma política pública mobilizadora, capaz de provocar mudanças, sistematizar o planejamento e coordenar o processo de desenvolvimento local, regional, estadual e nacional de forma articulada e compartilhada. Para implementar esse modelo é necessária a organização de um espaço geográfico em regiōes, para fins de planejamento, gestão, promoção e comercialização integrada e compartilhada da atividade turística. (Brasil, 2004, p.11)

No Mato Grosso do Sul, as regiões que possuem infraestrutura para recepção de turistas e, consequentemente, o maior número de pessoas envolvidas e dependentes desse setor são: a região Caminho dos Ipês, que compreende o núcleo receptor de Campo Grande; região Pantanal (Corumbá, Aquidauana e Miranda); e a região Bonito/Serra da Bodoquena que possui como núcleo receptor o município de Bonito. Cabe destacar que esses núcleos receptores de turistas passaram por transformações socioespaciais que vão desde a construção de aeroportos e rodovias, infraestrutura para acesso e permanência de turistas como hospedagens e restaurantes, além dos serviços de transporte, lazer, comércio e acompanhamento de turistas. Conforme apontado por Cruz (2003, p. 25) "o turismo é capaz de reorganizar sociedades inteiras para que ele possa acontecer".

Nessa perspectiva, justifica-se o recorte, para fins de análise das consequências da pandemia no turismo, de três municípios, ou seja, Bonito, Jardim e Bodoquena (Figura 1). Estes são integrantes da região turística Bonito/Serra da Bodoquena, foi. A escolha se deve ao fato de que nesse espaço geográfico criado e/ou apropriado para o uso turístico existe uma diversidade de pessoas trabalhando em atividades ligadas ao turismo e prestação de serviços correlacionados. As principais atividades desenvolvidas nesses municípios são: de contemplação (observação de flora e fauna), esportes radicais (rapel, parapente, mergulho em cavernas, bóiacross, rafting, mountain bike, trekking), passeio e descanso. E, conforme compreende Lozato-Giotart (2021), a atratividade turística de um determinado território é favorecida pelo seu ambiente, o qual é composto por elementos humanos e naturais. O mapa a seguir (Figura 1) apresenta a localização dos municípios foco do presente estudo. 


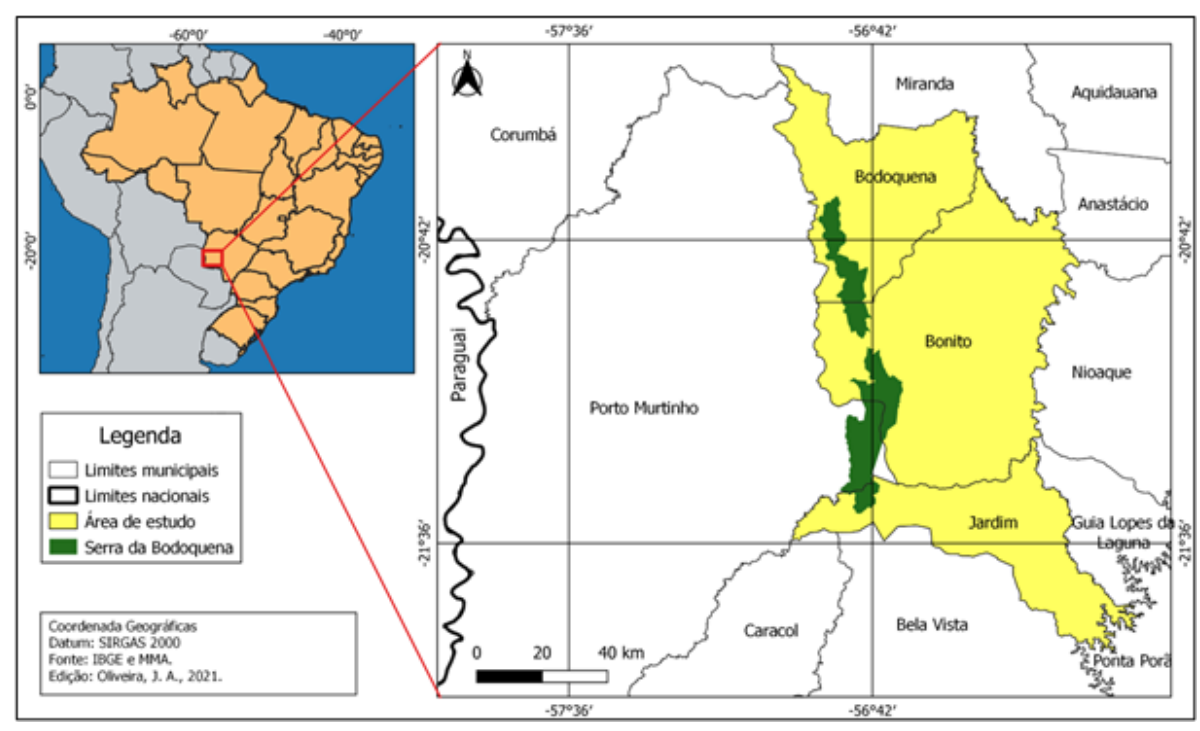

FIGURA 1

Mapa de localização dos municípios analisados.

Elaborado pelos autores

Até março do ano de 2020, a região turística de Bonito/Serra da Bodoquena se mantinha como um importante roteiro turístico internacional, sobretudo pela valorização de sua condição de ambiente natural. A pandemia da covid-19 acarretou suspensão da atividade turística em todo o país, tida como uma das atividades econômicas mais retráteis diante das crises, conduzindo os/as empresários/as do turismo a uma reorganização econômica e deixando os/as trabalhadores/as em condição de vulnerabilidade social.

Em 11 de março de 2020, o diretor da Organização Mundial de Saúde decreta estado de pandemia do novo coronavírus, considerando os mais de 118 mil novos casos distribuídos por 114 países (WHO, 2020). Conforme orientações da Organização Mundial da Saúde, a partir do reconhecimento da existência do coronavírus e das suspeitas da sua alta taxa de disseminação, foram realizados, por diversas nações, os fechamentos de fronteiras e demais medidas restritivas à circulação de pessoas. Alguns especialistas acreditam que esse vírus já estava circulando no Brasil, apesar do primeiro registro de caso ter ocorrido em fevereiro de 2020.

Note-se que somente no dia 12 de março ocorreu o primeiro óbito confirmado, um dia após a Organização Mundial da Saúde (OMS) decretar pandemia pelo novo coronavírus (Sars-CoV-2). No prazo de uma semana as primeiras medidas relacionadas ao setor turístico foram tomadas. (Novaes et al., 2021, p. 71).

No Mato Grosso do Sul, os dois primeiros casos de covid-19 foram confirmados pela Secretaria Estadual de Saúde (SES) no dia 14 de março de 2020, sendo que sua interiorização ocorreu de forma lenta. Os municípios de Bonito, Jardim e Bodoquena apresentaram seus primeiros casos somente no mês de maio. Contudo, conforme exposto por Novaes et al. (2021, p. 72),

Neste período, a Secretaria de Estado de Saúde do MS alertou para interiorização dos casos de coronavírus, próximo ao Parque Nacional da Serra da Bodoquena, onde houve o crescimento exponencial na incidência de casos. Nas vizinhanças de Jardim e Bonito houve um verdadeiro surto epidêmico localizado no município de Guia Lopes da Laguna, onde foram contabilizados 990 casos por 100 mil habitantes, sendo que este município tem uma população estimada de 9.824 pessoas (Ibge, 2020). Também foi confirmado o aumento de casos em Bonito, 63 casos por 100 mil habitantes, e Jardim, com 76 casos por 100 mil habitantes.

Ainda que os primeiros casos tenham sido registrados apenas em maio, por meio dos decretos municipais, as atividades do trade turístico foram suspensas no mês de março, considerando o seu alto potencial de aglomeração de pessoas. Diversas atividades que também lucram com o turismo, como boates, danceterias 
e salões de festas, casas de festas e eventos, atrativos turísticos públicos e privados, meios de hospedagens, incluindo os cadastrados no Airbnb e outras plataformas digitais, clubes de serviço e de lazer, feiras, exposições, congressos, seminários, parques de diversão e parques temáticos, pubs, tabacarias e congêneres, foram suspensas. O tempo de duração da suspensão oficialmente corresponde ao período de 90 dias consecutivos, tendo sido proposto um retorno facultativo em junho, porém, a maioria dos estabelecimentos retornou em agosto de 2020.

A pesquisa que originou este artigo constituiu-se por ampla pesquisa bibliográfica referente ao lugar da pesquisa e às condições da pandemia, pesquisa documental realizada em sites dos órgãos oficiais de turismo das prefeituras municipais, Observatório do Turismo de Mato Grosso do Sul, Instituto Brasileiro de Geografia e Estatística (IBGE) e Fundação de Turismo de Mato Grosso do Sul. Devido à nossa posição de evitar encontros presenciais desnecessários para levantamento de dados primários, realizamos entrevistas semiestruturadas por diversos meios, como telefone, e-mail e redes sociais, com empresários do setor, representantes das prefeituras, membros de associações vinculadas ao turismo e órgãos oficiais de turismo, entre novembro e dezembro de 2020, e aplicamos questionário, em março de 2021, por meio do Google Forms, com questões abertas e fechadas, direcionado a Guias de Turismo.

O referencial teórico deste trabalho apoiou-se na ciência geográfica e utilizou outras ciências como a estatística, a economia e estudos específicos sobre turismo para o entendimento da reorganização espacial ou paralisação do turismo e atividades ligadas ao turismo.

Partindo do pressuposto de que o turismo de massa é um fenômeno do século XX, não se pode ignorar sua possível relação com as pandemias ocorridas de lá para cá, não apenas como um setor impactado pelas mesmas, mas também como um potencial vetor de seu espalhamento pelo planeta, configurando-se, nesse caso, uma relação dialética. (Cruz, 2020, p. 2).

Apesar da relação dialética estabelecida por Cruz (2020) entre as pandemias e o turismo de massa, assim como em seu artigo, este estudo não tem como objetivo olhar para a disseminação da pandemia associada ao turismo, mas analisar os seus impactos sobre o setor. A autora aponta ainda que "[...] a covid-19 invade a escala do corpo humano, atravessa o mundo, produz regióes com maiores ou menores níveis de contágio e impacta nações, regiões e lugares de formas distintas, conectando, de diferentes formas, essas diferentes escalas" (Cruz, 2020, p. 4). Quanto a essas diferenças, cabe fazer uma breve comparação das atividades turísticas da região Bonito/Serra da Bodoquena com as do Pantanal sul-mato-grossense, que, para além de enfrentar, durante o ano de 2020, restrições de viagens, medidas restritivas e o isolamento social, também teve agravantes como o fechamento da fronteira e as queimadas.

O conceito de região utilizado neste texto apoiou-se no conhecimento geográfico, pois, conforme aponta Silva $(1995$, p. 28, 30), é uma de suas “[...] categorias fundamentais [...]” e “[...] posterior à categoria território, porque a região é o território já ocupado e onde se desenvolveu uma organização do espaço que o torna determinação de um modo de vida". Kayser (1975, p. 279) complementa afirmando que, "[...] qualquer que seja o modo pelo qual for considerada ou a utilidade que lhe for atribuída, a região é de qualquer forma um fenômeno geográfico".

O conceito de região está presente em diversas áreas do conhecimento, e cada uma delas "[...] traz sua própria leitura sobre a região, o regionalismo e/ou a regionalização" (Haesbaert, 2014, p. 9). De acordo com Andrade (1999, p. 11), apesar de "região" ser "[...] uma categoria que interessa a vários ramos do conhecimento", ela "[...] tem um peso muito grande na reflexão geográfica”. Por fim, esse entendimento de região "[...] é de uso fluido [...]", "[...] faz parte do senso comum [...]" e está presente nas "[...] conversas comuns do dia a dia [...]” (Lencioni, 1999, p. 16-17). Desta forma, a concepção de região aqui trabalhada encontra respaldo tanto na ciência geográfica quanto nas expressões do fazer laboral dos atores entrevistados. 


\section{IMPACTOS DA COVID-19 NA REGIÃo TURÍSTICA DE Bonito/SERRA DA BoDOQUENA}

Para subsidiar nossa análise sobre os impactos da pandemia da covid-19 na região estudada, realizamos levantamento de dados por meio de entrevistas e questionários destinados a sujeitos/as que trabalham no turismo nos municípios de Bonito, Jardim e Bodoquena. A coleta de dados contemplou 26 guias de turismo que atuam diretamente na região analisada, um/a representante do governo estadual, três representantes dos governos municipais (um de cada município), três empresários de atrativos turísticos, um empresário/a do ramo hoteleiro e um/a empresário/a de agência de turismo. Tal descrição tem por finalidade apresentar e analisar o resultado da amostra. Nossos respondentes não serão identificados no texto, apenas nomeados pela letra " $R$ ", de respondente, seguida de um número sequencial que corresponderá aos participantes da pesquisa. Cabe ressaltar que, para a coleta com os guias de turismo, as questóes abertas, respondidas por eles próprios, tiveram uma análise de conteúdo para serem posteriormente classificadas e apresentadas nesta discussão.

As entrevistas realizadas com os representantes municipais ligados ao setor do turismo vão ao encontro das respostas dos guias de turismo e empresários, contudo, algumas respostas devem ser analisadas devido às percepções e às ações efetivadas. As suspensões das atividades com potencial de aglomerações, incluindo o trade turístico, iniciaram-se no dia 17 de março de 2020 em dois dos municípios: Bonito, conforme Decreto Municipal no 091/2020, e Jardim, mediante Decreto Municipal nº24/2020. No município de Bodoquena, conforme relato de um representante vinculado à Secretaria de Turismo, o fechamento das atividades ligadas ao turismo iniciou-se no dia 15 de março de 2020 e prolongou-se pelos meses de abril, maio e junho (pouco mais de 3 meses), tendo estas retornado apenas em $1^{\circ}$ de julho de 2020. Adicionalmente, o representante ligado ao turismo de Bodoquena aponta que:

Diminuiu significativamente a circulação de pessoas (turistas e moradores) nas lanchonetes e similares, principalmente no período da noite. Alega que os comerciantes ficaram "um pouco revoltados", a Prefeitura implantou o toque de recolher das $20 \mathrm{~h}$ às $5 \mathrm{~h}$, sendo permitido o funcionamento apenas de drogarias e posto de combustível. (R1, entrevista com representante do município de Bodoquena ligado ao turismo, realizada em 07/12/2020).

Os atrativos turísticos permaneceram fechados por aproximadamente 90 dias contados a partir dos decretos municipais. Como podemos observar na afirmação de R2, "fechei o atrativo, os turistas não apareciam devido às estradas estarem fechadas. Não havia perspectivas, também pouco posso afirmar que nossos gestores tiveram preocupação com nosso setor" (R2, entrevista realizada em 2020). Os impactos no setor turístico também afetaram de forma indireta o comércio local, sobretudo do município de Bonito, conforme aponta um dos entrevistados: "cabe destacar que o comércio local sentiu sobremaneira o fechamento prolongado do segmento turístico e que o fechamento dos hotéis trouxe impactos negativos no abastecimento de serviços e de pequenas lojas que dependem dos vendedores" (R3, entrevista realizada em 2020).

Quando questionados sobre se a gestão pública municipal havia produzido e/ou implementado políticas para o enfrentamento da crise no setor de turismo naquele momento da pandemia, o representante do município de Bonito foi o único a dar uma resposta incisiva: "sim, o poder público deflagrou uma série de ações relacionadas ao setor de turismo e comércio em geral, como prorrogação dos prazos para pagamento do ISSQN[2], REFIC[3], apoio a elaboração dos protocolos de biossegurança" (R3, entrevista realizada em 2020). Ele relatou, ainda, que as políticas direcionadas aos trabalhadores formais e informais do turismo foram "especialmente aos guias e transportadores turísticos, houve fornecimento de cestas básicas pela secretaria de assistência social. Só para estes dois setores o número de cestas/mês chegou à casa de 300 cestas" (R3, entrevista realizada em 2020).

$\mathrm{Na}$ cidade de Jardim, não houve medidas direcionadas aos trabalhadores do turismo por parte da prefeitura, somente ações de prevenção à covid-19. O/A representante do município ligado/a ao turismo relatou que "cada empresa adotou medidas relacionadas à segurança tanto dos trabalhadores formais, como 
dos terceirizados, sendo disponibilizados álcool, máscaras e atenção aos sinais de síndromes gripais” (R4, entrevista realizada em 2020). Na entrevista com um proprietário de uma agência de turismo, este apontou que não houve respaldo do município no período, nem para a empresa nem para os trabalhadores.

\footnotetext{
Não houve nenhuma política que incentivou as empresas de turismo ou do segmento, a não ser a limitação ou fechamento dos passeios que foram feitos, muito dificultou a nossa vida. Nem mesmo [d]o alvará municipal fomos isento, tivemos que pagar da mesma forma quanto ao governo federal apenas aquela ajuda [...] de amparo ao convite e governo estadual. Não ouvi nada de forma a beneficiar o turismo, agente de turismo, guias, nada, nenhum amparo foi feito. (R5, entrevista com proprietário de uma agência de turismo, realizada em 23/11/2020).

De forma geral, não recebemos nenhum incentivo. Apenas exigências. Quando houve a possibilidade de reabertura, tivemos que adequar o nosso ambiente a critérios, tendo, assim, que apresentar um Projeto de Biossegurança. Em resumo, não recebemos nenhum suporte em nenhuma instância ( $\mathrm{R} 2$, entrevista com proprietário de um atrativo turístico, realizada em 17/11/2020).
}

Quando o mesmo questionamento foi feito ao representante de Bodoquena, este relatou que tiveram como estratégia, ou intenção, ter o menor número de casos possível da covid-19 no município, pois as pessoas pesquisariam quais as cidades com o menor número de casos para visitar. Sendo assim, descreveu que as medidas tomadas foram: manutenção do fechamento/restrição do município por mais tempo (ele acredita que Bonito aumentou o número de casos por terem aberto mais cedo); ações de conscientização aos turistas e aos empresários locais, principalmente sobre o uso de máscaras; estabelecimento de barreira sanitária com identificação dos moradores por meio de adesivos, tendo em vista que o controle de circulação ajudou a retardar a proliferação do número de casos; constituição de um comitê para enfrentamento da pandemia. Porém, esse comitê apenas repassou o plano de biossegurança, ficando a cargo dos próprios atrativos os treinamentos e orientaçóes aos trabalhadores sobre o plano (R1, entrevista realizada em 2020).

Sobre os principais desafios e limitações para a implementação dessas políticas para o enfrentamento da crise no setor de turismo no momento, o depoente indicou: "disponibilidade de recursos, aporte real de recursos estaduais e federais, que mesmo anunciados na grande mídia, não chegaram de fato nos municípios" (R3, entrevista realizada em 2020). Em relação às articulaçóes do município com o Órgão Oficial de Turismo do Estado e o Ministério do Turismo para o enfrentamento da crise e para a elaboração de estratégias para o pós-pandemia, os relatos vão de "nenhuma articulação" à transição de gestão pública, passando por tentativas não concretizadas, conforme pode ser percebido nas falas dos representante municipais: "não houve nenhuma articulação própria do setor do turismo para o enfrentamento da pandemia, apenas no caso das ações gerais. Inclusive o município recebeu recursos para enfrentamento da pandemia, mas, não específico para o setor do turismo" (R1, entrevista realizada em 2020); "existem tratativas no calor da pandemia, muita conversa e pouco horizonte de ações concretas" (R3, entrevista realizada em 2020); "atualmente, estamos em fase de transição da gestão pública. Acredito que algumas ações permanecerão em andamento e outras novas surgiram" (R4, entrevista realizada em 2020).

O/A proprietário/a de atrativo turístico fez uma crítica às políticas de amparo dos diferentes níveis da federação, apontando que recebeu auxílio "apenas do SEBRAE com selo Turismo Seguro e Fundação de Turismo com campanha de marketing e máscaras". Ainda acrescenta como sugestão em relação às políticas públicas que poderiam ter sido ou podem ser implementadas para o enfrentamento da crise gerada pela covid-19, "vacinação da gripe não só para grupos prioritários ou incluir profissionais do turismo no grupo prioritário" (R6, entrevista realizada em 2020).

Em relação aos empregos de seus funcionários, os donos de atrativos relatam não ter efetuado as demissões durante o período de fechamentos dos empreendimentos, mas foram necessárias algumas medidas como "suspensão e férias coletivas" (R7, entrevista realizada em 2020). Outro relato revela que não demitiram, "contudo, acabamos com nossas reservas de dinheiro" (R6, entrevista realizada em 2020). Um dos entrevistados apontou: 
Quanto à demissão, não fizemos nenhuma, pois trabalhamos com guia autônomo prestador de serviço e a nossa equipe, como é familiar, acabou assimilando o prejuízo da não demissão de nenhum funcionário, mas foi difícil para os nossos guias, pois não tinha trabalho e também não tinha nenhuma reserva econômica. A grande maioria passou até mesmo necessidades”. (R5, entrevista com proprietário de uma agência de turismo, realizada em 23/11/2020).

No município de Bodoquena, os guias ( 16 cadastrados) foram bastante afetados pela pandemia, sobretudo porque sua renda depende da circulação dos visitantes nos atrativos turísticos. Conforme relatado, eles ficaram "parados" em relação ao seu trabalho, porém, foi necessário que procurassem outras fontes de renda e meios de sobrevivência, tendo trabalhado, assim, com outras atividades até o retorno, mesmo que gradativo, do turismo no município (R1, entrevista realizada em 2020). Nesse relato, fica evidente a falta de articulação local devido a proposta do governo federal de oferecer um auxílio emergencial para trabalhadores de todos os setores, mas cabe lembrar que nem todos conseguiram a liberação do benefício.

Um representante do município de Bodoquena ligado ao turismo aponta que a Prefeitura pensou em ofertar um subsídio aos guias, porém, foi suprido pelo auxílio emergencial. Sendo assim, não levaram adiante a proposta, considerando que os guias também foram atendidos pelo auxílio federal, pois ele "veio para todos". Argumentou que, como os guias podem abrir empresas como MEI [4], ficava "mais fácil” de conseguir o auxílio) (R1, entrevista com representante do município de Bodoquena ligado ao turismo, realizada em $07 / 12 / 2020)$.

Todos os 26 guias de turismo relataram atuar na cidade de Bonito (principal destino turístico da região analisada), enquanto em Bodoquena e Jardim atuam 10 e nove guias, respectivamente. No entanto, 15 guias declararam atuar somente em Bonito (cerca de $58 \%$ da amostra) e outros seis apontaram trabalhar nos três municípios pesquisados. Outros sete municípios foram mencionados por 12 guias. Em média, a área de atuação dos guias de turismo contempla 2,2 municípios.

É importante ressaltar que o tempo de atuação na atividade é elevado, resultando em 19,7 anos de média. O trabalhador com mais tempo de serviço já havia completado 35 anos de exercício e o com menos tempo tinha quatro meses (em março de 2021, quando a coleta foi realizada). Dentre eles, 15 guias possuíam mais de 21 anos de serviço na profissão, seis possuíam entre 11 e 20 anos, e outros cinco tinham até 10 anos de trabalho na função. Podemos perceber, então, que temos uma amostra extremamente qualificada, e que conhece profundamente o setor turístico na região estudada. A Tabela 1 nos apresenta o perfil de atuação profissional dos guias de turismo da região. 
TABELA 1

Perfil de atuação profissional dos guias de turismo da região

\begin{tabular}{|c|c|}
\hline Descricão & $\%$ \\
\hline \multicolumn{2}{|c|}{ Municípios de atuação } \\
\hline Alcinópolis & $3,8 \%$ \\
\hline Aquidauana & $7,7 \%$ \\
\hline Bodoquena & $38,5 \%$ \\
\hline Bonito & $100,0 \%$ \\
\hline Campo Grande & $7,7 \%$ \\
\hline Corumbá & $7,7 \%$ \\
\hline Dourados & $3,8 \%$ \\
\hline Jaraguari & $3,8 \%$ \\
\hline Jardim & $34,6 \%$ \\
\hline Miranda & $11.5 \%$ \\
\hline \multicolumn{2}{|c|}{ Quantilade de municípios emque atua profiesiomlmente } \\
\hline Apenas em Bonito & $57,7 \%$ \\
\hline Em 3 municipios & $26,9 \%$ \\
\hline Em 4 municipios & $3,8 \%$ \\
\hline Em 5 municipios & $3,8 \%$ \\
\hline Em 6 municipios & $3,8 \%$ \\
\hline Em 7 municipios & $3.8 \%$ \\
\hline \multicolumn{2}{|c|}{ T empo de atuação profísioml } \\
\hline Até 10 anos & \begin{tabular}{|l|l|} 
& $19,2 \%$ \\
\end{tabular} \\
\hline de 11 a 20 anos & $23,1 \%$ \\
\hline mais de 21 anos & $57.7 \%$ \\
\hline
\end{tabular}

Elaborado pelos autores a partir da coleta de dados.

Todavia, como em todos os lugares, a covid-19 impactou profundamente na atividade laboral pois, desde que foi decretada a pandemia, interrompendo o turismo nos municípios de atuação, apenas quatro declararam não ter paralisado as atividades, o que corresponde a cerca de 15,4\% dos entrevistados. Porém, quase em igual medida, 3 ficaram totalmente sem trabalho, o equivalente a 11,5\% do total de 26 profissionais. Um destes informou que mudou de profissão depois de 23 anos atuando no "Ecoturismo". Como se evidencia, não eram profissionais de pouco tempo de serviço. Entre os outros dois que permaneceram por mais de um ano sem exercer a sua função (do início da pandemia em março de 2020 até a coleta de dados em março de 2021), um possuía 12 anos de experiência, e o outro, 20 anos.

Para os demais, que totalizavam 19 entrevistados, ou o equivalente a 73,1\% da amostra, o tempo de paralisação foi, em média, de 4,2 meses, com um tempo mínimo de três meses e máximo de oito meses (excetuando os 3 guias que pararam de trabalhar no setor turístico). Dentre esses trabalhadores que ficaram parte do ano de 2020 sem atuar com atividades do turismo, 15 retornaram “aos poucos", após os meses de interrupção, conforme relataram, e outros quatro esperaram mais alguns meses.

Sendo assim, para quase $85 \%$ dos guias de turismo entrevistados, a pandemia representou uma paralisação de, ao menos, três meses do ano, acarretando em uma diminuição significativa e, em alguns casos, total, do trabalho e geração de renda entre março de 2020 e março de 2021, mesmo após o retorno das atividades turísticas. Com exceção de um único guia de turismo, os demais, que representavam $96,2 \%$ do total, alegaram ter sua renda individual ou familiar diminuída durante a pandemia. Destes, 22 sujeitos, ou 84,6\% dos respondentes, tiveram que complementar a renda com outras atividades, por exemplo: sete recorreram a vendas de produtos (tal como sabonete artesanal, doces e salgados, etc), cinco prestaram serviços diversos, dois se desfizeram de bens, e ainda houve quem foi trabalhar de garçom, pedreiro, motoboy, professor particular, entre outras atividades.

É interessante apontar que o único guia de turismo que declarou não ter tido modificação em sua renda individual ou familiar é um dos mesmos que não teve sua atividade paralisada, apesar de impactada, e que afirmou ter mantido a sua rotina de trabalho "regular" (em sua definição) durante a pandemia. Porém, esta pessoa e outras 18 , totalizando 19 e representando $73,1 \%$ dos sujeitos da pesquisa, receberam algum tipo 
de ajuda para suportar os períodos de maiores dificuldades (principalmente a distribuição/entrega de cestas básicas). Sete respondentes, equivalente a $26,9 \%$ do total, informaram não ter recebido nenhum tipo de ajuda.

Outra forma de apoio/ajuda recebida indicada pelos entrevistados foi o auxílio emergencial disponibilizado pelo Governo Federal. Dos 26 entrevistados, apenas seis não solicitaram o auxílio $(23,1 \%)$ e outros quatro $(15,4 \%)$ solicitaram, mas não receberam, totalizando 10 pessoas não beneficiárias do auxílio governamental. No entanto, 16 guias (61,5\%), receberam o auxílio emergencial. Ainda considerando outras formas de apoio, questionamos se, ao retornarem ao trabalho, eles receberam algum tipo de material de proteção ou prevenção ao contágio e contaminação da covid-19. Apenas 18 deles (69,2\%) receberam algum material, porém, apenas máscara e álcool em gel. Vale destacar que a principal entidade que fez tal distribuição foi a Associação de Guias de Turismo de Bonito, conforme relatado por eles.

Como em diversas áreas de nossa sociedade, percebemos que a pandemia escancarou o distanciamento entre o poder público e a população. Nesse sentido, percebemos que nem em municípios que possuem a atividade turística como uma importante atividade econômica os profissionais do ramo receberam equipamentos de proteção individual para o contato e atendimento aos turistas. Isso é corroborado quando apenas seis guias declararam ter recebido alguma visita de representantes da Secretaria de Saúde para prestar esclarecimentos sobre a pandemia.

Pudemos perceber que a contaminação era uma preocupação presente na vida dos entrevistados, pois aproximadamente $85 \%$ deles declaram ter alguém da família ou pessoa próxima, quando não foi a própria pessoa, contaminada com covid-19. Observa-se na Tabela 2 os impactos da pandemia da covid-19 na vida e cotidiano dos guias pesquisados. 
TABELA 2

Impactos e consequências da pandemia da covid-19 na vida e cotidiano dos guias de turismo da região

\begin{tabular}{|c|c|}
\hline Descriç̃o & $\%$ \\
\hline \multicolumn{2}{|c|}{ Paralisou as atividades } \\
\hline$\overline{\mathrm{Sim}}$ & $84,6 \%$ \\
\hline Não & $15.4 \%$ \\
\hline \multicolumn{2}{|c|}{ T empo de parallisação } \\
\hline até 4 meses & $78,9 \%$ \\
\hline Mais de 4 meses & $21.1 \%$ \\
\hline \multicolumn{2}{|c|}{ Precisou fazer outra ativilade } \\
\hline Não & $15,4 \%$ \\
\hline$\underline{\text { Sim }}$ & $84.6 \%$ \\
\hline \multicolumn{2}{|c|}{ Qunis atividades } \\
\hline Vendas & $31,8 \%$ \\
\hline Serviços diversos & $22,7 \%$ \\
\hline Vendeu bens & $9,1 \%$ \\
\hline Garçom & $4,5 \%$ \\
\hline Motoboy & $4,5 \%$ \\
\hline Serviços rurais & $4,5 \%$ \\
\hline Pedreiro & $4,5 \%$ \\
\hline Aula particular & $4,5 \%$ \\
\hline Aula de violão & $4.5 \%$ \\
\hline \multicolumn{2}{|c|}{ Recebeu ajula } \\
\hline Cesta básica/alimentos & $73,1 \%$ \\
\hline Näo & $26.9 \%$ \\
\hline \multicolumn{2}{|c|}{ Recebeu auxilio emergencinl } \\
\hline Eu pedi e recebi. & $61,5 \%$ \\
\hline Não pedi. & $23,1 \%$ \\
\hline Ev pedi, mas não recebi. & $15,4 \%$ \\
\hline \multicolumn{2}{|c|}{ Recebeu mnterial de protecão } \\
\hline$\overline{\mathrm{Sim}}$ & $69,2 \%$ \\
\hline Não & $30.8 \%$ \\
\hline \multicolumn{2}{|c|}{ Visita de repres, da Sec. de Saúde } \\
\hline$\overline{\text { Sim }}$ & $23,1 \%$ \\
\hline Não & $76.9 \%$ \\
\hline \multicolumn{2}{|c|}{ Teve corid-19 ou alguém da familia ou próximo } \\
\hline$\overline{\text { Sim }}$ & $84,6 \%$ \\
\hline Não & $15.4 \%$ \\
\hline
\end{tabular}

Elaborado pelos autores a partir da coleta de dados.

Ainda buscamos identificar junto aos guias de turismo qual foi a sua percepção em relação ao movimento quando do retorno às atividades e se os turistas eram provenientes de localidades próximas ou distantes da região. $\mathrm{O}$ resultado de tal percepção é apresentado na Tabela 3.

TABELA 3

Percepção dos guias de turismo em relação ao movimento e origem dos turistas na região

\begin{tabular}{|c|c|}
\hline De scrição & $\%$ \\
\hline \multicolumn{2}{|l|}{ Percpção da redução do movimento de turistas } \\
\hline Foi significativo, não parou, mas o movimento reduziu bastante. & $46,2 \%$ \\
\hline O flux o de turistas caiu para quase a metade. & $30,8 \%$ \\
\hline A redução foi total, parou completamente. & $23,1 \%$ \\
\hline \multicolumn{2}{|l|}{ Percepção da origem dos turistas } \\
\hline Todos/as eram de cidades próximas & $7,7 \%$ \\
\hline A grande maioria era de cidades próximas e uma pequena parte de outros lugares/Estados & $42,3 \%$ \\
\hline Eram em proporções parecidas (quase meio a meio) & $23,1 \%$ \\
\hline A grande maioria era de outros lugares/Estados e uma pequena parte de cidades próximas & $26,9 \%$ \\
\hline
\end{tabular}


Elaborado pelos autores a partir da coleta de dados.

Podemos observar que a redução foi sentida por todos, porém em intensidades distintas. Seis guias, ou $23,1 \%$, informaram que a redução do movimento percebida por eles foi "total", sendo que o fluxo em suas atividades "parou completamente". Destes que perceberam uma redução total, metade ficou sem trabalho ou teve que mudar de profissão, o que justifica tal percepção. Para 30,8\% dos guias de turismo, o fluxo reduziu quase pela metade, representando um impacto significativo em suas atividades laborais e de geração de renda, explicando a necessidade que tiveram de buscar alternativas para complementar o sustento familiar.

Em se tratando da percepção que tiveram em relação à origem dos turistas que passaram a frequentar a região após a retomada das atividades, a maior proporção, equivalente a 42,3\%, acredita que "a grande maioria era de cidades próximas". Se somado aos que perceberam que "todos/as eram de cidades próximas", temos $50 \%$ dos guias apontando que a maior parte do fluxo de turistas são das "redondezas" da região. Mesmo aqueles que entendem que a origem dos turistas foi equilibrada entre cidades próximas ou distantes, 23,1\% delas reforça que proporcionalmente temos a maioria dos turistas oriundos de perto da região estudada. Ademais, analisando inversamente, aqueles que identificaram como a maior parte de turistas sendo de localidades distantes, representam apenas $26,9 \%$ dos sujeitos entrevistados.

O setor hoteleiro foi um dos setores ligados ao turismo que também sofreu um grande impacto, assim como os trabalhadores deste setor que tiveram que fazer acordos de suspensão dos serviços por um tempo ou entraram em férias coletivas. $\mathrm{Na}$ cidade de Jardim, conforme relato da pessoa entrevistada, quando questionada sobre o impacto da covid-19, relatou: "impacto super negativo, a empresa fechou por determinado período e após a reabertura operou abaixo dos $20 \%$ de ocupação” (R7, empresário/a de um hotel). O/A entrevistado/a refere-se a um período de fechamento de 2 duas semanas. A Figura 2, a seguir, representa a taxa de ocupação dos hotéis em Bonito no ano de 2020.

FIGURA 2

Taxa de ocupação dos hotéis de Bonito/MS no ano de 2020.

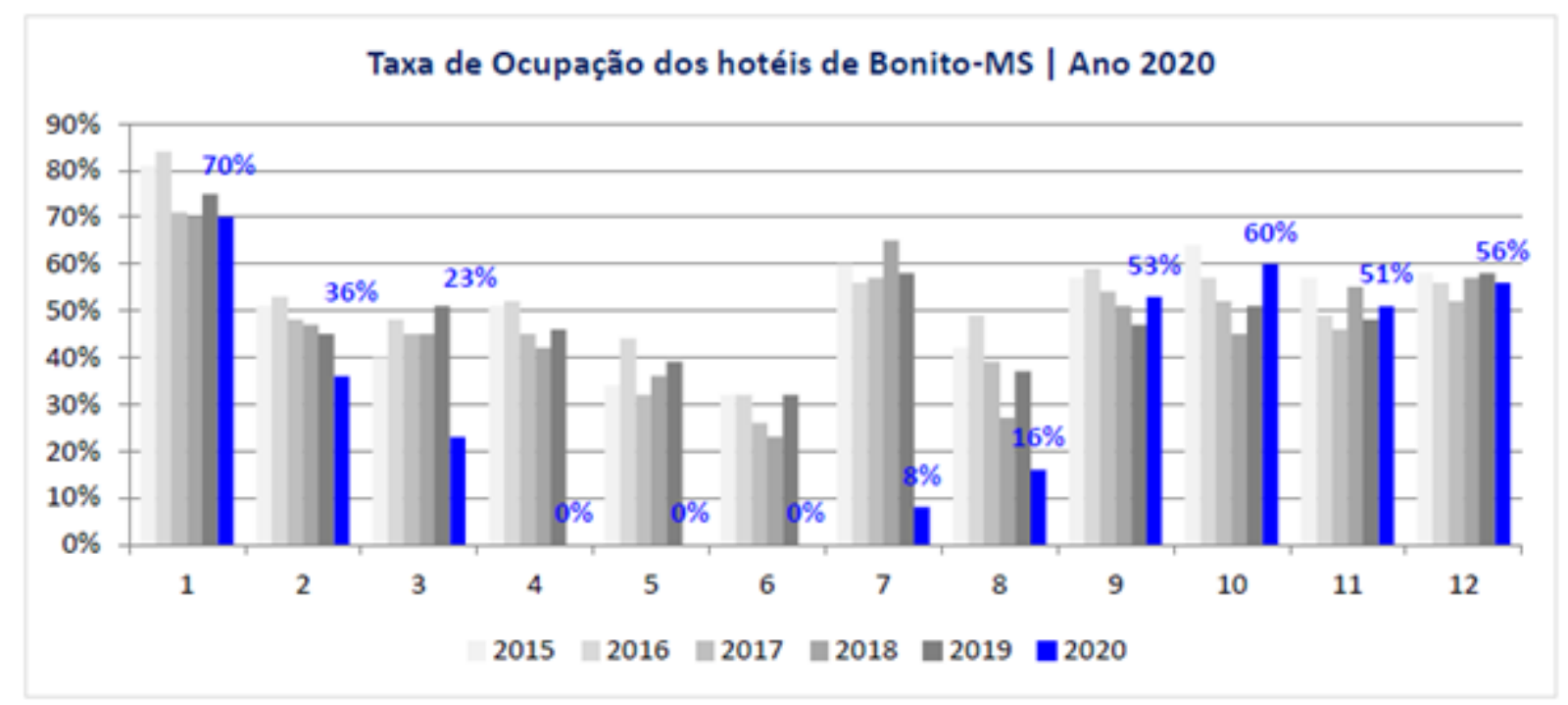

Observatório do Turismo e Eventos de Bonito-OTEB (2020).

Conforme pode ser verificado, ao analisarmos dados disponíveis no Observatório do Turismo e Eventos de Bonito (OTEB) (2020), estes demonstram que a taxa de ocupação dos hotéis em Bonito, de fevereiro a agosto, ficou abaixo dos 50\% de ocupação, sendo que no mês de julho (férias escolares) essa taxa foi de 8\%, bem inferior ao ano anterior (58\%). Em setembro, as taxas começam a elevar-se, inclusive acima das taxas do ano de 2019. 
Quanto aos turistas, em setembro, o fluxo destes voltou a aumentar consideravelmente, sobretudo no feriado da Independência do Brasil, no qual foi estimado mais de 10 mil pessoas em Bonito. $\mathrm{O}$ mês de setembro de 2020 (20.946 visitantes) superou o número de visitantes em comparação aos últimos cinco anos, até mesmo o ano de 2016 (19.281 visitantes), que até então apresentava os maiores valores (OTEB, 2020). Os meses de outubro (24.503 visitantes) e dezembro (23.822 visitantes) também superaram os cinco anos imediatamente anteriores, porém, no total acumulado, esses valores foram menores devido à paralisação total nos meses de abril, maio e junho; e a retomada lenta nos meses julho e agosto (OTEB, 2020).

Conforme o Boletim Retomada do Turismo em Mato Grosso do Sul do Observatório do Turismo de Mato Grosso do Sul (2021), a partir de informações sobre duas pesquisas realizadas no período de janeiro a março de 2021, quanto a procedência dos turistas, dos 95,6\% procedentes do Brasil, 35,2\% são do estado do MS e 64,8\% de outros estados, destacando São Paulo (21,5\%), Paraná (11,7\%) e Rio de Janeiro (7,8\%). Esses dados, somados aos dados relativos ao modos de deslocamento, demonstram distâncias curtas entre origem e destino. Considerando que a maioria chega a Bonito com o próprio carro, de amigos ou parentes (60,2\%), para 96,3\% dos sul-mato-grossenses essa foi a opção mais utilizada; avião até Campo Grande (28\%) ou avião até Bonito (9,2\%) (OBSERVATÓRIO DO TURISMO DE MS 2021).

Quanto aos questionamentos sobre o fato de as pessoas se sentirem seguras para viajar, o Observatório do Turismo de MS (OBSERVATÓRIO DO TURISMO DE MS, 2021) demonstra que 89,9\% dos visitantes de Bonito responderam que se sentiram seguros com os protocolos de biossegurança adotados. Desta forma, constatamos que o inimigo invisível realmente é percebido pela maioria das pessoas somente na testagem, quando positiva ou na internação hospitalar.

\section{CONSIDERAÇÕES FINAIS}

Ainda que a pandemia do novo coronavírus tenha sido prejudicial a diversos setores da economia, o setor do turismo foi especialmente atingido devido à redução drástica na circulação de pessoas. Corroborando com Lozato-Giotart (2021), o qual expressa que a maioria dos atores que produzem e consomem as atividades turísticas de lazer devem considerar prioritários os desdobramentos sociais e econômicos. Neste texto, apresentamos a análise de consequências da propagação deste vírus, o inimigo oculto, para as pessoas direta e indiretamente ligadas ao setor do turismo na região de Bonito/Serra da Bodoquena.

Demeyère (2020) considera a existência de grande oportunidade de transformar o trabalho no setor do turismo devido as questões colocadas pela crise da pandemia, mas pondera que essa oportunidade pode ir para segundo plano devido a necessidade de rápida recuperação da economia. O Secretário-Geral da Organização Mundial do Turismo, Zurab Pololikashvili, também compreende que esta crise deve ser vista como uma oportunidade para "repensar o setor do turismo e sua contribuição para as pessoas e o planeta", e ainda, se reconstruir como um setor mais sustentável e inclusivo, visando garantir "que os benefícios do turismo sejam desfrutados de forma ampla e justa” (UNWTO, [s.d.]).

Em nossa pesquisa, os representantes do turismo dos três municípios estudados (Bonito, Bodoquena e Jardim) alegaram que a resposta à expansão do coronavírus foi imediata por meio dos decretos de encerramento das atividades com potencial de aglomeração, tendo sido fechados temporariamente os atrativos turísticos, hotéis, bares, restaurantes e toda a estrutura do trade turístico. Os empresários, em contrapartida, proprietários/as de agências de turismo, hotéis e de atrativos turísticos, apontaram a falta de incentivo e a ausência de ações específicas para o setor do turismo nesses municípios. As políticas passíveis de serem observadas e que foram efetivadas correspondem às ações do município de Bonito, que deflagrou a prorrogação dos prazos para pagamento do ISSQN, REFIC e apoio à elaboração dos protocolos de biossegurança, medidas não somente destinadas ao setor do turismo, mas ao comércio em geral.

Os profissionais autônomos, guias vinculados sobretudo aos atrativos turísticos, foram os mais afetados economicamente pela pandemia. As pessoas envolvidas com turismo alegaram preocupação com aqueles 
trabalhadores, os quais foram obrigados a redirecionar a sua atividade laboral e receberam contribuições do município de Bonito, como a distribuição de cestas básicas. O representante do poder público do município de Bodoquena, vinculado à Secretaria de Turismo, relatou que quando refletiram sobre a situação dos guias, optaram por orientá-los a pensar em se registrar como MEI, para, então, receber o auxílio emergencial.

Por meio da coleta de dados junto aos 26 guias de turismo atuantes na região analisada, foi possível perceber que a maioria dos guias atua exclusivamente no município de Bonito, polo da região turística Bonito/Serra da Bodoquena, sendo que $80,8 \%$ destes profissionais possui experiência superior a 10 anos. Por meio de suas respostas, evidenciamos que $84,6 \%$ deles paralisou totalmente as suas atividades, recebendo apenas auxílios como cestas básicas e alimentos, e apenas $61,5 \%$ pediu e recebeu o auxílio emergencial do governo federal. Esses profissionais também encontraram como alternativa para complementar suas rendas outras atividades como vendas, serviços diversos (estes não especificaram a atividade), garçom, motoboy, serviços rurais, aulas particulares, chegando à máxima de vender alguns bens.

Igualmente impactado, o setor hoteleiro ficou sem hóspedes durante os meses determinados pelos decretos, e, após o período, operou bem abaixo de sua capacidade, de modo que os trabalhadores destes empreendimentos acabaram por ter seus serviços suspensos ou receberam férias coletivas. Somente em setembro de 2020 as taxas de ocupação dos hotéis em Bonito começaram a elevar-se, inclusive acima das taxas do ano de 2019. Esse mês corresponde a um momento marcante, sobretudo pelo feriado da independência brasileira, no qual o número de visitantes no município foi igual ou superior à sua média histórica. Este fato representou um alerta em relação ao contágio pelo coronavírus, exigindo repensar sobre a abertura dos estabelecimentos e a forma de controle para a prática do turismo. Durante os meses seguintes, o fluxo de turistas para a região continuou elevado, igualando as médias históricas de visitantes.

As reflexões realizadas com base nos dados levantados, nas entrevistas e nos questionários aplicados, permitem afirmar que, durante o período de março a setembro de 2020, a região turística Bonito/Serra da Bodoquena vivenciou um período de diminuição drástica do fluxo de turistas, com a paralisação das atividades do setor, impactando fortemente na vida das pessoas vinculadas ao turismo. Tal paralisação foi agravada pela precariedade do trabalho no setor turístico, com insegurança quanto ao futuro do trabalho na atividade. Posteriormente, a partir de setembro de 2020, verificamos o retorno das atividades no setor, com mudanças em algumas características pontuais como adequação das hospedagens e dos atrativos. Outra percepção foi em relação à busca do lugar como um destino adequado para visitação, principalmente pelo fato do turismo na região ser valorizado como um destino de natureza e apresentar possibilidades de hospedagem "isolada", portanto, considerado pelos visitantes como mais seguro quanto à proteção contra a covid-19.

É importante destacar que as condições de trabalho no setor, com forte presença da sazonalidade no emprego, provocam instabilidade aos trabalhadores quanto à possibilidade de manutenção do tipo de trabalho e condições de ganhos salariais adequados, e que a falta de garantia no mundo do trabalho provocou insegurança nos momentos mais críticos do fechamento dos atrativos.

\section{REFERÊNCIAS}

Abbas, J.; Mubeen, R.; Iorember, P.T.; Raza, S.; Mamirkulova, G. (2021). Exploring the impact of COVID-19 on tourism: Transformational potential and implications for a sustainable recovery of the travel and leisure industry. Current Research in Behavioral Sciences, 2, 100033.

Andrade, M. C. de. (1999). Prefácio. In: Lencioni, S. Região e Geografia. São Paulo, SP: EDUSP, Ed. da Universidade de São Paulo (Coleção Acadêmica), pp. 11-14.

Brasil, Ministério do Turismo. (2019). Rotas turísticas estratégicas do Programa Investe Turismo (p. 6). Ministério do Turismo. https://www.gov.br/turismo/pt-br/centrais-de-conteudo/rotas-tursticas-estratgicas-investeturismopdf. Acesso em: 27 jul 2021. 
Joyce Avila de Oliveira, et al. Consequências da pandemia da Covid-19 para as pessoas do Setor de ...

Brasil, Ministério do Turismo, Embratur, Instituto Brasileiro de Turismo, \& SEBRAE, Serviço Brasileiro de Apoio às Micro e Pequenas Empresas. (2019). Programa Investe Turismo: Parcerias para transformar destinos. MTur, SEBRAE, EMBRATUR. https://www.gov.br/turismo/pt-br/centrais-de-conteudo/mtur-cartilha-investe-turi smo-pdf. Acesso em: 27 jul 2021.

Brasil. (2020a)._Lei n. 13.979, de 06 de fevereiro de 2020. Disponível em: http://www.planalto.gov.br/ccivil_03/_ato 2019-2022/2020/lei/113979.htm. Acesso em: 27 jul 2021.

Brasil. (2020b). Portaria no 454, de 20 de março de 2020. Disponível em: https://www.in.gov.br/en/web/dou/-/port aria-n-454-de-20-de-marco-de-2020-249091587. Acesso em: 16 set 2020.

Cruz, R. C. A. (2003) Introdução à geografia do turismo. 2 ed. São Paulo: Roca.

Cruz, R. de C. A. da. (2020). O evento da covid-19 e seus impactos sobre o setor turismo: Em busca de uma análise multi e trans-escalar. Revista Acadêmica Observatório de Inovação Do Turismo, 14(4), 1-15. https://doi.org/10 .17648/raoit.v14n4.6636. Acesso em: 02 jul. 2021.

Demeyère, C. (2020). Tourisme post COVID-19, conditions de travail et précarité dans le secteur touristique. Téoros, v. 39, n³ 2020. [Online]. Disponível em: http://journals.openedition.org/teoros/7457. Acesso em: 25 set. 2021.

Gössling, S.; Scott, D.; Hall, C. M. (2020). Pandemics, tourism and global change: A rapid assessment of COVID-19. Journal of Sustainable Tourism. https://doi.org/10.1080/09669582.2020.1758708. Acesso em: 25 set. 2021.

Haesbaert, R. (2014). Regional-Global: dilemas da região e da regionalização na geografia contemporânea. 2a ed. Rio de Janeiro, RJ: Bertrand Brazil.

Kayser, B. (1975). A região como objeto de estudo da geografia In: George et al. (Orgs.) A Geografia Ativa. 4a ed. São Paulo, SP: DIFEL - Difusão Europeia do Livro, Editora da Universidade de São Paulo, pp. 279-321.

Lencioni, S. (1999). Região e Geografia. São Paulo, SP: EDUSP, Ed. da Universidade de São Paulo (Coleção Acadêmica).

Lozato-Giotart, J. P. (2021). Tourisme et environnement: priorites et limites pour quel optimum? une problematique incontournable. In: CHÁVEZ, E. S; MORETTI, E. C. (org.). Apropriação e mercantilização da natureza na produção de territórios turísticos. [livro eletrônico]. Porto Alegre, RS: Totalbooks.

Novaes, A. L., Moretti, E. C., Oliveira, J. Á. de, Gonçalves, K. B., \& Ribeiro, M. A. (2021). Turismo e a pandemia de covid-19 no Mato Grosso do Sul. In CRUZ, R. C. A et al. (Orgs.). Turismo em tempos de covid-19: Ensaios sobre casos na Argentina, Brasil, Moçambique e Portugal (p. 71-78). FFLCH/USP. https://doi.org/10.11606/97865 87621456. Acesso em: 26 jul. 2021.

Observatório do turismo de MS. (2019). Boletim de dados turísticos de Mato Grosso do Sul 2019. ed. 05, jan./fev./mar. 2019. Disponível em: http://www.observatorioturismo.ms.gov.br/wp-content/uploads/2019/07/BoletimDad osTuristicosMS_jan-fev-mar_2019.pdf. Acesso em: 02 jul. 2021.

Observatório do turismo de MS. (2020). Boletim de dados turísticos de Mato Grosso do Sul 2020. ed. 09, jan./fev./mar. 2020. Disponível em: https://www.observatorioturismo.ms.gov.br/wp-content/uploads/2020/06/Boletim_ja n-fev-mar_2020.pdf. Acesso em: 02 jul. 2021.

Observatório do turismo de MS. (2021). Boletim retomada do Turismo em MS 2021. ed. 03, 2021. Disponível em: https://www.observatorioturismo.ms.gov.br/wp-content/uploads/2021/06/Boletim-Retomada-do-Turis mo-em-MS-Ed03-2021.pdf. Acesso em: 02 jul. 2021.

Observatório do turismo e eventos de Bonito. (2020). Boletim mensal OTEB. Disponível em: https://otbonito.com. br/wp-content/uploads/2021/01/OTEB-Boletim-2020_12.pdf. Acesso em: 02 jul. 2021.

Silva, A. C. da. (1995). As categorias como fundamentos do conhecimento geográfico. In: Reynaud; Santos; \& Souza (Orgs.). O Espaço interdisciplinar. 2a ed. Rio de Janeiro, RJ: Bertrand Brasil (Coleção Espaços), pp. 25-37.

UNWTO, World Tourism Organization. ([s.d.]). Tourism and COVID-19: Leading Tourism Recovery| UNWTO. UNWTO. Disponível em: https://www.unwto.org/tourism-covid-19. Acesso em: 25 set. 2021.

WHO. World Health Organization. (2020). WHO Director-General's opening remarks at the media briefing on COVID-19-11 March 2020. Disponível em: https://www.who.int/director-general/speeches/detail/who-direc tor-general-s-opening-remarks-at-the-media-briefing-on-covid-19---11-march-2020. Acesso em: 25 set. 2021. 
Caderno Virtual de Turismo, 2021, vol. 21, núm. 3, ISSN: 1677-6976

\section{Notas}

[1] Para saber mais sobre o grupo de pesquisa, consultar: https://sites.google.com/view/turismo-em-tempos-de-pandemia.

[2] O Imposto sobre Serviços de Qualquer Natureza, também conhecido como ISS.

[3] O Programa Especial de Renegociação de Dívidas, permitiu ao contribuinte da cidade de Bonito, mediante lei complementar, a adesão ao programa pode se realizar até a data de 31 de agosto de 2020, devido ao covid-19. Mais informações podem ser encontradas em: https://www.bonito.ms.gov.br/2020/08/05/prefeito-sanciona-lei-do-reficpara-dividas-ativas-de-2019-e-2020/

[4] Microempreendedor Individual, pessoa jurídica que trabalha por conta própria. 